\title{
O PRÉ-MODERNISMO: A LUTA ENTRE PASSADISTAS, MODERNOS E MODERNISTAS NO CAMPO ARTÍSTICO BRASILEIRO
}

Jean Marcel Oliveira ARAUJO

Universidade Federal Fluminense

vjmo@terra.com.br

Resumo: A partir de reflexões acerca do recorte temporal e do sentido com que se deve compreender o termo Pré-modernismo, o presente estudo analisa a situação de disputas e enfrentamentos por posições no campo artístico brasileiro, identificando agentes e suas práticas discursivas evidenciando, através da análise de textos da autoria desses agentes, propostas estéticas em conflito, segundo as quais grupos e indivíduos buscavam garantir legitimidade no referido campo.

Palavras-chave: Pré-modernismo. Campo artístico. Agentes. Práticas discursivas. Propostas estéticas.

Abstract: By means of reflections about this time frame, and the ways in which the term Pre-modernism should be understood, the current study analyzes the situation of quarrels and confrontations for positions in the Brazilian artistic field, identifying actors and their discursive practices, demonstrating through the analysis of texts written by these agents, aesthetic issues in conflict, according to which groups and individuals were trying to ensure legitimacy in the related field.

Keywords: Pre-modernism. Artistic field. Actors. Discursive practices. Aesthetic issues.

\section{Introdução}

O termo Pré-modernismo foi criado em 1939 por Tristão de Athayde (pseudônimo de Alceu Amoroso Lima, 1893-1983) para denominar o "momento de alvoroço intelectual, marcado pelo fim da grande guerra [1914-1918] e, entre nós, por toda uma ansiedade de renovação intelectual, que alguns anos mais tarde redundaria no movimento modernista" (ATHAYDE, 1939, p. 07). O momento a que se refere o crítico é o período compreendido entre 1916 e 1920, sobretudo, o ano de 1919. Com exceção de Notas de estudo: fragmentos (1916), de António Carlos Moreira Telles; $O$ preconceito de raça no Brasil (1916), de Álvaro Bomilcar (1874-1957), A união e o ensino primário (1918), de Antonio Monteiro de Souza (? -1936), Jardim da Europa (1918), de Agostinho de Campos (1870-1944), Problema vital (1918), de Monteiro

\begin{tabular}{|l|l|l|l|l|}
\hline Pensares em Revista & São Gonçalo, RJ & n. 1 & 117-134 & jul.-dez. 2012 \\
\hline
\end{tabular}


Lobato (1882-1948), e Fruta do mato (1920), de Afrânio Peixoto (1876-1947), as obras analisadas por Athayde são publicações do ano de 1919, a exemplo da coletânea Tarde, de Olavo Bilac (1865-1918). Anos depois, ele, em artigo publicado no Jornal do Brasil, em 11 de abril de 1975, delimitou com mais precisão o Pré-modernismo: período que se estende do último quartel do século XIX aos vinte e cinco anos do século XX (ATHAYDE, 2007, p. 356).

Desde sua criação, o Pré-modernismo tornou-se um tema controverso na história da literatura brasileira, em virtude da complexidade e heterogeneidade de sua produção cultural e da inadequação do termo. Situá-lo segundo orientações da teoria dos movimentos literários não é tarefa fácil, já que o Simbolismo "não foi mais do que um episódio", isto é, "não penetrou no espírito das classes cultas senão muito superficialmente, deixando intacta a formação parnasiana dominante" (BOSI, 1969, p. 12), e porque se questiona a Semana de Arte Moderna enquanto marco inicial do Modernismo brasileiro, conforme infere Sodré: “A Semana tem sido superestimada, [...] pois sua importância, meramente episódica, embora característica sob muitos aspectos do verdadeiro caráter do movimento, foi muito menos do que pretendem fazer crer alguns de seus participantes e alguns de seus cronistas" (SODRÉ, 1995, p. 525). Dessa forma, muitas são as tentativas de estabelecer um recorte temporal, bem como de atribuir um sentido ao termo.

No que diz respeito ao recorte temporal, ao procurar sintetizar as propostas de alguns autores (ATHAYDE, 2007; BOSI, 1969; 1994; CANDIDO, 1965; LAFETÁ, 1974; PESSIANI, 2003), encontro quatro possibilidades de delimitação. Na primeira, são considerados os marcos mais aos extremos: fins dos oitocentos (1890) a 1925. E, dessa forma, fariam parte do Pré-modernismo o Simbolismo e as manifestações da Semana de Arte Moderna (1922). Na segunda, passa-se a considerar dos fins dos oitocentos (1890) a 1922, excluindo-se as manifestações da Semana. Na terceira, considera-se o primeiro quartel do século XX, excluindo-se o Simbolismo, mas se incluem as manifestações da Semana. Já na quarta, leva-se, em consideração, um recuo tanto inicial quanto final em relação à primeira, considerando o princípio do século XX, isto é, a partir da publicação de Os sertões, de Euclides da Cunha (1866-1909), e Canãa, de Graça Aranha (1868-1931), em 1902, até as manifestações da Semana de Arte Moderna. Esta me parece ser a mais sensata, visto que as referidas obras são as

\begin{tabular}{|l|l|l|l|l|}
\hline Pensares em Revista & São Gonçalo, RJ & n. 1 & 117-134 & jul.-dez. 2012 \\
\hline
\end{tabular}


primeiras a apresentar uma mudança de orientação no que diz respeito ao alargamento do imaginário social, em virtude da incorporação de novos personagens e espaços sociais. E, mesmo tendo em vista os referidos questionamentos à sua supervalorização, a Semana, como procuro demostrar mais adiante, é o desfecho de embates travados no campo literário.

Já no que se refere ao sentido em que se deve compreender o Pré-modernismo, identifico abordagens que o tratam como movimento literário ou período de transição. Seguindo a trilha aberta por outros autores, a exemplo de Alaor Barbosa (1996), Enio Pessiani atribui ao Pré-modernismo o estatuto de movimento literário, como deixa entrever nesse questionamento: "Mas, o que significa dizer que Monteiro Lobato foi um escritor inserido no movimento literário conhecido como pré-modernismo?" (PESSIANI, 2003, p. 21). (Grifos meus).

Para Pessiani (2003, p. 22), em sua reavaliação do Pré-modernismo, este período da literatura brasileira foi mais que "simples anteparo do modernismo", mas um movimento que oferecia novidades, prenunciando elementos estéticos e temáticos, explorados mais tarde pelos modernistas. Ele identifica inovações referentes tanto a um projeto político quanto a um projeto estético. Do ponto de vista político, o "movimento" apresentava rupturas com os moldes da art nouveau, bem como tentativas de conhecimento do país a fundo através de linguagem nova - "a narrativa literária [...] se mostrou explicitamente como uma ferramenta para o conhecimento das condições reais do país" (PESSIANI, 2003, p. 44-45), além do repúdio à importação de escolas literárias e artísticas europeias; da atribuição de importância ao papel do escritor; do resgate de nossas raízes; da construção de uma ideia de nação e identidade nacional e do rompimento com o idealismo romântico.

Do ponto de vista estético, houve incorporação de elementos coloquiais da língua; rapidez no ritmo do texto literário; redução dos textos; incorporação da crônica como gênero literário; presença do leitor no texto, evidenciando, neste caso, a proximidade entre leitor e escritor e; diversificação do léxico pré-modernista pela incorporação de regionalismo, estrangeirismos, gírias, expressões populares e neologismos.

Desse modo, Pessiani arremessa o Pré-modernismo para fora do Modernismo, procurando compreendê-lo pelo que ele significou isoladamente e pelas relações com o tempo em que foram concebidas as obras dos autores, deixando de apresentar de que 
traços, tanto formais quanto ideológicos das "estéticas oitocentistas", os escritores do período pré-modernista, a exemplo de Monteiro Lobato, eram tributários, traços esses fundamentados na noção de arte como representação mimética do real. Ou seja, apesar das inovações, os autores não conseguiram romper completamente com traços conservadores que realimentam antigas formas de sensibilidade do leitor, marcadas, segundo João Luiz Lafetá, por uma "linguagem bacharelesca, artificial e idealizante que espelhava a consciência ideológica da oligarquia rural instalada no poder" (LAFETÁ, 1974, p. 13). Outro problema diz respeito à situação de autores, a exemplo de Afrânio Peixoto, Coelho Neto (1864-1934), Raul Leoni (1895-1926), João Simões Lopes Neto (1865-1916) e Xavier Marques (1861-1942), cujas obras acabam sendo desprestigiadas.

Diante da impossibilidade de atribuir ao Pré-modernismo o estatuto de movimento, alguns autores passam a compreendê-lo como um período de transição. Alfredo Bosi, por exemplo, atribuiu ao termo duas acepções possíveis, "nem sempre coincidentes" (BOSI, 1969, p. 11). Na primeira, mais cronológica, o prefixo "pré" indica apenas "uma conotação meramente temporal de anterioridade" (BOSI, 1969, p. 11), abrigando sob esse rótulo a produção literária dos "neos", que marcou o início do século XX: neoparnasianismo e neossimbolismo, na poesia; neorrealismo e neonaturalismo, na prosa de ficção. Sob essa acepção, consideram-se "muitos remanescentes da cultura realista-parnasiana" (Coelho Neto, Afrânio Peixoto, Xavier Marques e Raul Leoni), ou seja, o período "intervalar" entre o fim do Simbolismo e o início do Modernismo foi marcado por autores incapazes de mover as águas estagnadas de uma cultura oficial da Primeira República (BOSI, 1994, p. 197). Era uma literatura compatível com o modelo cultural oficial, importador e consumidor voraz dos produtos da cultura europeia e, por isso, alheia à diversidade cultural do país e, sobretudo, à cultura popular que "tinha muito a ver com a população ex-escrava, com a população negra, com a população marginal” (CARVALHO, 1988, p. 19).

$\mathrm{Na}$ segunda, mais estética, o prefixo indica "um sentido forte de precedência temática e formal em relação à literatura modernista” (BOSI, 1969, p. 11), ou seja, antecipação estética de algumas propostas modernistas, atribuindo à referida produção o adjetivo "moderno". O termo designa, neste caso, "tudo o que rompe, de algum modo, com essa cultura brasileira oficial, alienada e verbalista, e abre caminho para as sondagens sociais e estéticas retomadas a partir de 22" (BOSI, 1994, p. 197). Por essa 
razão, "se pode chamar de pré-modernismo (no sentido forte de premonição dos temas vivos em 22) tudo o que, nas primeiras décadas do século $[\mathrm{XX}]$, problematiza a nossa realidade social e cultural" (BOSI, 1994, p. 306). Nesse grupo, podem ser incluídos os nomes de Euclides da Cunha, Monteiro Lobato, Graça Aranha e Lima Barreto (18811922), na prosa, e Augusto dos Anjos (1884-1914) e Afonso Schmidt (1890-1964), na poesia. A estes coube "o papel histórico de mover as águas estagnadas da belle époque, revelando, antes dos modernistas, as tensões que sofria a vida nacional" (BOSI, 1994, p. 307). É o momento anterior ao Modernismo, que, "considerado na sua totalidade, enquanto crítica ao Brasil arcaico, negação de todo academicismo e ruptura com a Velha República, desenvolve a problemática daqueles, como o fará, ainda mais exemplarmente, a literatura dos anos de 30" (BOSI, 1994, p. 307).

Ao se denominar o Pré-modernismo um período de transição, acentua-se ainda mais a ineficácia da teoria dos movimentos literários, pois as obras e autores não se permitem capturar por tal lógica e acabam fora de classificação, privados dessa relativa segurança que vale a inserção numa ordem: pré-modernista pode significar moderno, naturalista, parnasiano, realista e/ou simbolista.

Há, por essa razão, a necessidade do estudo das obras do período, "pelo que significam isoladamente e pelas relações que guardam entre si e com o tempo em que foram concebidas” (LEITE, 1995, p. 169). Consciente de tal necessidade, eu procuro, então, compreender o Pré-modernismo como o período compreendido entre 1902 e 1922, momento marcado por conflitos por legitimidade no campo artístico brasileiro, sobretudo entre os representantes de uma arte alinhada aos valores clássicos, regidos por princípios imutáveis, leis fundamentais que não dependiam da latitude e do clima (LOBATO, 1964, p. 60) e; os representantes de uma crítica global às velhas estruturas mentais, negação do academicismo e ruptura com a cultura oficial, num esforço de penetrar mais fundo na realidade brasileira. Dessa forma, a partir dessa redefinição do Pré-modernismo, e com base na noção de campo (BOURDIEU, 1996), analiso a situação em que diferentes agentes disputavam posições, identifico alguns dos referidos agentes e suas práticas discursivas, evidenciando as propostas estéticas em conflito no campo literário brasileiro, segundo as quais grupos e indivíduos buscavam garantir sua legitimidade. 


\section{Os confrontos}

Com a Semana de Arte Moderna, os ideais dos artistas do grupo paulista, congregados em torno de Mário (1893-1945) e Oswald de Andrade (1890-1954) consolidaram-se no campo artístico brasileiro. Entretanto, até 1922, vários foram os eventos que marcaram o período pré-modernista, evidenciando confrontos entre grupos distintos. Em 1902, foram publicados Os sertões, de Euclides da Cunha, e Canaã, de Graça Aranha, que tratam, respectivamente, da Guerra de Canudos (Bahia) e da imigração alemão no Espírito Santo.

Em 1905, Lima Barreto estreia com O subterrâneo do Morro do Castelo. Mesmo severamente criticado pelos seus contemporâneos por seu estilo "despojado e descuidado", ele dá continuidade a sua obra, publicando Recordações do Escrivão Isaías Caminha (1909), As Aventuras do Doutor Bogóloff (1912), Triste Fim de Policarpo Quaresma e Numa e a ninfa (1915), Vida e Morte de M. J. Gonzaga de Sá (1919), Histórias e sonhos (1920) e Os Bruzundangas (1922); obras marcadas por uma crítica contudente a Velha República e pelo resgate das tradições cômicas, carnavalescas e picarescas da cultura popular.

Em 1911, Oswald de Andrade funda a revista humorística $O$ pirralho, contando entre os seus colaboradores Di Cavalcanti (1897-1976). Nesse periódico, foram parodiados vários poemas consagrados da literatura brasileira, como "Meus oito anos", de Casimiro de Abreu (1839-1860), e "Canção do Exílio", de Gonçalves Dias (18231864). No ano seguinte, ele retorna da Europa, trazendo em sua bagagem ideias do Futurismo de Filippo Tommaso Marinetti (1876-1944). Neste mesmo ano, João Simões Lopes Neto publica Contos Gauchescos e Augusto dos Anjos publica, com a ajuda do irmão Odilon dos Anjos, seu único livro de poesias, Eu, com tiragem de 1.000 exemplares.

Em 1913, Lasar Segall (1891-1957) realizava uma exposição com suas telas em São Paulo, dentre as quais a tela "Figura", mas não alcançou grande repercussão nos meios artísticos. No ano seguinte, após retornar da Alemanha, Anita Malfatti (18891964) realiza sua primeira exposição, cujas telas apresentam traços marcadamente expressionistas. Três anos mais tarde, 12 de dezembro de 1917, após viagem aos Estados Unidos, onde conhece a obra do pintor cubista Abraham Solomon Baylinson

\begin{tabular}{|l|l|l|l|l|}
\hline Pensares em Revista & São Gonçalo, RJ & n. 1 & 117-134 & jul.-dez. 2012 \\
\hline
\end{tabular}


(1882-1950), ela realizou uma segunda exposição com 53 trabalhos (pinturas, aquarelas, gravuras e caricaturas), contando entre as telas "O homem amarelo", "O japonês", "A boba", "A estudante russa" e "A mulher de cabelos verdes".

Criticando severamente a exposição de Anita Malfatti, Monteiro Lobato publicou, no jornal $O$ Estado de S. Paulo, em sua edição de 20 de dezembro de 1917, o artigo intitulado "Paranóia ou Mistificação?”, com subtítulo “A propósito da exposição Malfatti”. Reconhecendo na jovem pintora uma artista talentosa, independente, original e inventiva, ele a aconselha a mudar de postura, a abandonar "uma atitude estética forçada no sentido das extravagâncias de Picasso \& Cia” (LOBATO, 1964, p. 60). Seu objetivo não era atacar Anita Malfatti, mas ridicularizar a arte moderna, sob a influência das vanguardas artísticas europeias: Cubismo, Futurismo e Impressionismo.

Em sua crítica, o escritor de Taubaté divide os agentes do campo artístico em duas espécies de artistas. Da primeira, fazem parte aqueles "que veem normalmente as coisas e em conseqüência fazem arte pura" (LOBATO, 1964, p. 59). São "sóis imorredouros" por terem gênio e satélites que gravitam em torno daqueles sóis, se têm apenas talento. São grandes mestres que devem ser seguidos. Fazem arte enquanto imitação da natureza, apreendida através dos cincos sentidos, pois, conforme Lobato, "um artista diante de um gato não poderá 'sentir' senão um gato; é falsa a 'interpretação' que do bichano fizer um totó, um escaravelho ou um amontoado de cubos transparentes" (LOBATO, 1964, p. 60). Ele pensa a arte como representação fiel da realidade, a coisa e sua representação devem apresentar simetria, pois todas as artes "são regidas por princípios imutáveis" (LOBATO, 1964, p. 60).

Conforme Hegel, o fim essencial da obra de arte da concepção artística defendida por Lobato "consistiria na hábil imitação ou reprodução dos objetos tal como existem na natureza, e a necessidade de uma reprodução assim feita em conformidade com a natureza seria uma origem de prazer” (HEGEL, 1996, p. 26), atribuindo à arte uma finalidade puramente formal, a de refazer, com os meios de que dispõe o homem, o que existe no mundo natural tal como captado pelos sentidos. A reprodução da natureza pela arte possuía um valor e um lugar. O artista deveria aprender a conhecer e reproduzir, nos mínimos detalhes, as formas e figuras dos objetos, com a finalidade de aproximar suas criações do belo natural. 
A segunda espécie de artista, segundo Lobato, é formada por aqueles "que veem anormalmente a natureza e a interpretam à luz das teorias efêmeras, sob a sugestão estrábica de escolas rebeldes" (LOBATO, 1964, p. 59). Surgem como furúnculos da cultura excessiva. "São produtos do cansaço e do sadismo de todos os períodos de decadência; são frutos de fim de estação, bichados ao nascedoiro. Estrelas cadentes, brilham um instante as mais das vezes com a luz do escândalo, e somem-se logo nas trevas do esquecimento" (LOBATO, 1964, p. 59). Tal arte, anormal e teratológica, nasce com a paranóia e a mistificação. Seu lugar é o manicômio, pois, enquanto ornamento de paredes, é produto lógico dos cérebros transtornados: arte sincera. Fora deles, nas exposições públicas zabumbadas pela imprensa, "não há sinceridade nenhuma, nem nenhuma lógica, sendo tudo mistificação pura” (LOBATO, 1964, p. 60). Comungando dos preceitos dessa "arte anormal e teratológica", Malfatti deixou-se, segundo Lobato, seduzir pelas teorias da arte moderna (escudo sob o qual se justifica qualquer borracheira) e, ao penetrar domínios de um impressionismo discutibilíssimo, "pôs todo o seu talento a serviço de uma nova espécie de caricatura", cujos ramos são as vanguardas europeias. Diferente da verdadeira arte caricatural, seja na forma seja na cor, ela tem por finalidade "desnortear, aparvalhar, atordoar a ingenuidade do expectador" (LOBATO, 1964, p. 61).

Embora Lobato identifique dois tipos de artistas, apenas a produção do primeiro grupo recebe o título de arte. É interessante observar que ele construiu sua autoridade não somente pela depreciação das práticas dos artistas da "Arte moderna", mas também procurou definir quem são os verdadeiros artistas modernos: "Como se não fossem moderníssimos esse Rodin que acaba de falecer, deixando após si uma esteira luminosa de mármores divinos; esse André Zorn, maravilhoso virtuose do desenho e da pintura; esse Brangwyn, gênio rembrandtesco da babilônia industrial que é Londres; esse Paul Chabas, mimoso poeta das manhãs, das águas mansas e dos corpos femininos em botão" (LOBATO, 1964, p. 62).

Lobato representava e defendia os artistas orientados pela visão clássica de arte, segundo a qual o belo artístico deve corresponder ao belo natural. Exemplo da busca por essa correspondência entre arte e natureza pode ser percebido no poema "A um poeta", publicado em 1919 no livro Tarde, de Olavo Bilac, embora ele já prenuncie aspectos da Modernidade defendidos por Charles Baudelaire (1821-1867). Em tal livro, o lirismo de

\begin{tabular}{|l|l|l|l|l|}
\hline Pensares em Revista & São Gonçalo, RJ & n. 1 & 117-134 & jul.-dez. 2012 \\
\hline
\end{tabular}


Bilac sofre um influxo crepuscular, sua atitude espiritual começa a diluir-se (Cf. BOSI, 1969, p. 19): o eu lírico exalta seu nacionalismo, sobreleva os ardores sensuais em declínio e avulta as sombras de uma tarde de outono. Contudo, o poeta mantém a perspectiva parnasiana de influência francesa, aliada à tradição lusitana.

Composto de catorze versos decassílabos, bem ao gosto clássico, distribuídos em dois quartetos e dois tercetos, o poema de Bilac sintetiza o ideal poético parnasiano. $\mathrm{O}$ eu-lírico começa por descrever as condições ideais para o trabalho de criação poética: manter-se longe do estéril turbilhão da rua, no aconchego do claustro e no sossego: "Longe do estéril turbilhão da rua, / Beneditino escreve! No aconchego / Do claustro, na paciência e no sossego" (BILAC, 1978, p. 205). O trabalho do poeta assim associa-se ao sacerdócio, pois, tal qual um monge beneditino isola-se do mundo para orar, o poeta isola-se para escrever. Como a realidade já não mais pode ser decifrada nem em termos mitológicos nem teológicos (GULLAR, 1989), o poeta se propõe decifrá-la por meio do trabalho árduo: “Trabalha e teima, e lima, e sofre, e sua!” (BILAC, 1978, p. 205). A atividade criadora não cabe mais aos gênios, como defende Lobato, mas ao homem comum dedicado. Escrever não é lazer, é trabalho. E requer dedicação, persistência e paciência, como requisitos indispensáveis para a obtenção da expressão perfeita, por isso o poeta deve teimar nessa busca desgastante, sofrida e angustiante.

O verso precioso seria, assim, o resultado de um cuidadoso trabalho de lapidação, precisa ser limado. Contudo, o poema deve se impor de forma natural, não deixando transparecer o emprego do esforço do poeta. O resultado poético deve ser igual a um templo grego, rico, mas sóbrio. Assim, como a poesia clássica e neoclássica, a poesia parnasiana deve evitar exageros, sendo simétrica, harmônica e simples. Natural. As estrofes devem ser cristalinas, dobradas ao jeito do ourives. O poema sairia da oficina sem defeitos, como todo objeto de arte.

Nesse sentido, o eu-lírico dialoga com o discurso que se corporifica nos versos do rondó (poema formado por quadras) "Profissão de Fé", publicado por Bilac no início da carreira, nos quais há comparação entre o trabalho do poeta e o trabalho do ourives: "Invejo o ourives quando escrevo / Imito o amor / Com que ele, em ouro, o alto relevo / Faz de uma flor. // Imito-o. E, pois, nem de Carrara / A pedra firo: / O alvo cristal, a pedra rara, / O ônix prefiro" (BILAC, 1978, p. 05). Há, com o emprego do verbo limar, a reafirmação da ideia parnasiana de que o poeta é um artesão da palavra: “Torce, 
aprimora, alteia, lima / A frase; e, enfim, / No verso de ouro engata a rima, / Como um rubi” (BILAC, 1978, p. 205). O poeta deve esmerar-se na busca da perfeição métrica, de rima rara e do preciosismo vocabular. O eu-lírico criado por Bilac é obcecado pela forma, chegando a reduzi-la a uma norma: a supervalorização da técnica artística, levada a cabo pelos neoparnasianos.

Fechando o poema com chave de ouro, o eu lírico evidencia três preceitos para o fazer artístico: gêmea da verdade, a beleza reside na forma; inimiga do artifício, a arte pura agrada pelo efeito natural e a força e a graça são produtos da simplicidade. Tais preceitos remetem ao ideal parnasiano que busca a Beleza e a Perfeição Formal na descrição de objetos destituídos de sentimento, cujo objetivo final era a "Arte pela Arte". O soneto "A um poeta", ao sintetizar o ideal parnasiano também explicitado em "Profissão de Fé", traça o percurso figurativo do fazer poético parnasiano, de uma poesia presa a formas e normas, cujos "dogmas" são a perfeição, o preciosismo, o enrijecimento formal, a supervalorização do fazer poético enquanto técnica e a minúcia do trabalho poético.

Assim, tanto no artigo de Monteiro Lobato, quanto no poema de Olavo Bilac, o poder está fundado no fato de seus princípios configurarem um modelo a ser imitado e reconhecido a partir de uma combinação singular de tradição, autoridade e influência. Por essa razão, pode-se associar as duas espécies de artistas, definidas e caracterizadas por Lobato, aos conceitos "estabelecidos" e outsiders cunhados por Elias \& Scotson (2000). Como se percebe na crítica de Lobato, os artistas da primeira espécie, os estabelecidos, se autopercebem, reconhecendo-se como os verdadeiros produtores da arte pura, mais poderosa e melhor: os mestres a serem seguidos são os guardiões do bom gosto no campo artístico. Fundam seu poder e distinção no fato de sua arte ser o retrato da natureza, eterna e imutável. Em oposição a eles, estariam os artistas de segunda espécie, os outsiders, marginalizados dentro do campo, por fazerem uma arte que não se enquadra nos preceitos estabelecidos pela primeira espécie de artista da qual Lobato e Bilac fazem parte: imitar a natureza.

Contestando tais princípios defendidos por Monteiro Lobato e Olavo Bilac, Mário de Andrade, em seu "Prefácio Interessantíssimo", que introduz a coletânea de poemas de Paulicéia Desvairada em 1922, revisa, num misto de blague e sinceridade, a tradição herdada dos movimentos literários pretéritos em que se formou como poeta, percebendo 
a necessidade de escrita livre. Embora tenha ciência de que não "pode se libertar duma só vez das teorias-avós que bebeu" (1974, p. 14), ele acredita no "lirismo, nascido no subconsciente, acrisolado num pensamento claro ou confuso" (ANDRADE, 1974, p. 17), criador de frase que são versos inteiros, sem prejuízo de medir tantas sílabas, com acentuação determinada. Tal postura o faz aproximar-se do Surrealismo proposto por André Breton dois anos mais tarde:

SURREALISMO. S. m. Automatismo psíquico puro pelo qual se exprime, quer verbalmente, quer por escrito, que de outra maneira, o funcionamento real do pensamento. Ditado do pensamento, na ausência de qualquer controle exercido pela razão, fora do âmbito de qualquer preocupação estética ou moral (BRETON, 1985, p. 47).

O Surrealismo se propôs ser um meio de conhecimento para a exploração de "tudo o que fosse o reverso da lógica e estivesse fora do controle da consciência" (HELENA, 1993, p. 57). Esta é a postura adotada pelo poeta do desvairismo, pois, quando sente a impulsão lírica, ele escreve "sem pensar tudo o que seu inconsciente lhe grita" (ANDRADE, 1974, p. 13).

Mário de Andrade define, então, o lirismo como "estado afetivo - visinho (sic) da sublime loucura" (ANDRADE, 1974, p. 26), cuja naturalidade é prejudicada pela preocupação métrica e de rima. Ele o fundamenta nas raízes do ato criador: "Esteticamente: fui buscar entre as hipóteses feitas por psicólogos, naturalistas e críticos sobre os primitivos das eras passadas, expressão mais humana e livre da arte" (ANDRADE, 1974, p. 29). Constrói uma teoria que rompe com o rigor formal e procura incorporar uma nova técnica: “A inspiração é fugaz, violenta. Qualquer impecilho (sic) a perturba e mesmo emudece. Arte, que, somada a Lirismo, dá Poesia, não consiste em prejudicar a doida carreira do estado lírico para avisá-lo das pedras e cercas de arame do caminho" (ANDRADE, 1974, p. 18).

E evocando a fórmula de "Lirismo + Arte = Poesia", Mário de Andrade procura valorizar a inspiração e dar autonomia ao seu lirismo, um lirismo contrabandista que não se submete nem às regras formais nem às regras gramaticais: "A gramática apareceu depois de organizadas as línguas. Acontece que meu inconsciente não sabe da existência de gramáticas, nem de línguas organizadas. E como Dom Lirismo é contrabandista...” (ANDRADE, 1974, p. 28). Usa as palavras em liberdade,

\begin{tabular}{|l|l|l|l|l|}
\hline Pensares em Revista & São Gonçalo, RJ & n. 1 & 117-134 & jul.-dez. 2012 \\
\hline
\end{tabular}


apresentando pontos em contato com o Futurismo de Marinetti, pois escrever arte, para o autor do "Prefácio Interessantíssimo", não significa jamais representar a vida atual no que tem de exterior: automóveis, cinema, asfalto. Se estas palavras frequentam o seu livro moderno, elas têm nele sua razão de ser (ANDRADE, 1974, p. 18-19). Ele escreve não para imitar a realidade, mas para refratá-la. Afastando-se do conceito conservador de arte, ele infere que o belo artístico será tanto mais artístico, tanto mais subjetivo quanto mais estiver afastado do belo natural, este, por ser imutável e objetivo, é eterno como a natureza. Ao contrário deste, o belo artístico é arbitrário, convencional e transitório, é uma questão de moda. "A arte não consegue reproduzir a natureza, nem este é o seu fim" (ANDRADE, 1974, p. 19). Ele adota uma postura em oposição à postura artística conservadora de Lobato. Por mais que os artistas consigam perceber a realidade através dos cinco sentidos, eles, ora conscientes, ora inconscientes, deformam a natureza.

Ao distinguir belo natural de belo artístico, Mário de Andrade dialoga com as proposições de Georg Wilhelm Friedrich Hegel (1996), para as quais existe uma diferenciação fundamental entre o belo artístico e o belo natural. Se este é regido por princípios eternos e imutáveis, o belo artístico é superior por ser uma criação do espírito que comunica esta superioridade aos seus produtos e à arte. O belo da arte está relacionado com a pureza do espírito e não à submissão à realidade da natureza. Nesta perspectiva, o belo artístico excluí o belo natural, uma vez que não há como o espírito desenvolver suas potencialidades se todas as condições da natureza estão determinadas por leis rígidas. Hegel defende o interesse estético do belo artístico: o belo da arte é um produto do espírito, por isso só pode ser encontrado na subjetividade dos seres humanos e em suas produções artísticas. Se Hegel se opõe à opinião que considera a beleza criada pela arte inferior à da natureza, Mário de Andrade a ele se alinha, opondo-se às opiniões de Lobato e de Bilac, que consideram a proximidade da beleza artística em relação à natureza: imitar é a maior virtude da beleza artística.

Para o autor de Macunaíma, a arte não tem por finalidade reproduzir a natureza: "Nossos sentidos são frágeis. A percepção das coisas exteriores é fraca, prejudicada por mil véus, provenientes das nossas taras físicas e morais: doenças, preconceitos, indisposições, antipatias, ignorâncias, hereditariedade, circunstâncias de tempo, de lugar, etc..." (ANDRADE, 1974, p. 22). Ele se nega a trilhar pela senda dos grandes 
mestres, nem quer se tornar um: "Não pretendo obrigar ninguém a seguir-me [...] não quero discípulos" (ANDRADE, 1974, p. 22; 32). Luta por uma expressão nova, que não esteja presa às formas do passado e subserviente aos grandes mestres, luta esta travada também por Manuel Bandeira com os mestres parnasianos, que ele satiriza no poema “Os sapos", publicado em Carnaval (1919) e declamado por Ronald de Carvalho na Semana de Arte Moderna.

Esse rondó imperfeito desencadeia um movimento em direção ao que o poeta alcançou com Libertinagem (1930). Refratando o campo literário brasileiro do primeiro quartel do século XX, o discurso do eu lírico de Bandeira põe em evidência como a arte, sobretudo a poesia, não deveria ser. Desenvolvendo-se num tom prosaico em que o eulírico observa uma cena, o poema inicia-se quando sapos saem da penumbra e se envolvem em uma contenda. O primeiro a se pronunciar é o sapo-boi. Representante da cultura europeia, ele procura impor sua autoridade através do berro e do urro, ao evocar uma tradição palaciana ("Meu pai foi rei”) e bélica ("Meu pai foi à guerra") para adquirir legitimidade. Porém, seguem-se, às suas falas, manifestações de desconfiança, que acabam pondo em dúvida seu poder: “'Não foi!' - 'Foi!' - 'Não foi!'” (BANDEIRA, 1996).

O segundo a se pronunciar é o sapo-tanoeiro (aguado). Ele constrói sua autoridade, ao descrever a sua poética, demonstrando os preceitos da poesia parnasiana, aos quais ele tece elogios. O seu fazer poético é exaltado e valorizado: "Meu verso é bom / frumento sem joio" (BANDEIRA, 1996). Os termos "parnasiano", "cancioneiro", "rima", "verso", "poesia", "artes poéticas", "norma" e "forma" evidenciam o percurso figurativo de poética parnasiana. Isso porque, como sinalizei antes, uma das principais preocupações na composição poética era a precisão das palavras, chegando ao ponto de serem criadas verdadeiras línguas artificiais. O esteticismo exige uma forma perfeita quanto à construção e à sintaxe. Esse culto à forma é percebido na sexta estrofe: "Vai por cinquenta anos / Que lhes dei a norma: / Reduzi sem danos / A fôrmas a forma" (BANDEIRA, 1996).

Os sapos-pipas, representações dos poetas parnasianos menores ou neoparnasianos, são os próximos a se pronunciar. Para usar as palavras de Lobato, estes seriam como satélites a gravitarem em torno dos grandes mestres. Observa-se que, diferente dos anteriores, estes se manifestam em conjunto, como um todo, por não 
apresentarem características particulares significativas. São poetas epigônicos. Seguem os preceitos parnasianos, não demonstrando traços de estilo significativos para além do modelo. Sua função é a defesa dos ideais dos grandes mestres, como o sapo-boi e o sapo-tanoeiro. Segundo Bosi, os neoparnasianos representavam "indício de pobreza cultural ou de insensibilidade às angústias do próprio tempo, aquele fechar-se na gaiola dourada dos catorze versos e cultivar um descritivismo requintado ou um lirismo de curto fôlego" (BOSI, 1969, p. 20).

Embora cada um queira defender sua posição dentro do campo, a saparia concorda em um ponto: a poesia foi substituída pelas artes poéticas, pelas maneiras de se fazer poesia. Ou seja, na busca pela expressão perfeita, a saparia adota uma postura cética, segundo a qual o fazer poético decorre da predominância das técnicas de composição sobre a poesia, da forma sobre o conteúdo; da procura da rima rica, rara ou preciosa, da combinação de categorias gramaticais diferentes, evitando-se temos cognatos. Segundo Almeida (2007), esses atores estão em conjunção com um determinado objeto-valor: a poesia que eles defendem e com a qual estão em conjunção. Os sapos (boi, tanoeiro, pipas) foram manipulados por um destinador (campo literário) que passou a eles seus valores e os fazem escrever suas poéticas segundo normas e princípios rígidos. Todos procuram entrar em conjunção com valores existentes no seu grupo social e inscritos na poesia.

Afastado desta contenda, encontra-se o sapo-cururu, marginalizado por não ter se submetido às regras do fazer poético parnasiano. Adota uma postura solitária como bem explicou Mário de Andrade em seu prefácio. Este último sapo é uma representação do poeta não-parnasiano, neste caso, modernista. Como o parnasianismo era o estilo literário em voga no campo, aquele que não se submetesse a ele era ignorado e ridicularizado, como aconteceu tanto com os simbolistas quanto com os primeiros modernistas. De acordo com Bosi (1969, p. 19), a permanência da linguagem parnasiana no primeiro quartel do século XX brasileiro era justificada por ter o parnasianismo se tornado "o estilo das camadas dirigentes, da burocracia culta e semiculta, das profissões liberais habituadas a conceber a poesia como 'linguagem ornada', segundo padrões já consagrados que [garantiam] o bom gosto da imitação". Daí os poetas modernistas da primeira geração terem se voltado contra os poetas parnasianos, procurando destruí-los. 
Essa tentativa é bem evidente no poema. Nele, os já referidos versos do rondó "Profissão de Fé”, de Olavo Bilac, são parodiados. O próprio Manuel Bandeira explica o seu emprego: “A propósito desta sátira, devo dizer que a dirigi mais contra certos ridículos pós-parnasianismos. É verdade que nos versos 'A grande arte é como lavor de joalheiro' parodiei o Bilac de 'Profissão de fé' (Imito o ourives quando escrevo)" (BANDEIRA, 1984, p. 61). Os ridículos a que se refere Bandeira são Hermes Fontes (1888-1930), que chamara a atenção do publico no prefácio de Apoteoses (1908) para o fato de não haver nos seus versos rimas de palavras cognatas, e Goulart de Andrade (1881-1936), que publicara poemas em que adotara a rima francesa com consoante de apoio (consoante que precede a vogal tônica). Ao retomar o poema de Olavo Bilac, imitando-o em seus aspectos formais, Bandeira inverte seu sentido numa atitude irônica. Imita-o comicamente de forma burlesca. Seu objetivo foi atribuir ao poema original uma nova situação: o das disputas no interior do campo literário. Ao expor os preceitos e técnicas adotados pelos poetas parnasianos para legitimar suas posições no campo artístico, o faz com desdém, expondo seus propagadores ao ridículo. Ao associar o conteúdo da sexta estrofe com o da terceira, o tom de paródia à estética parnasiana é reforçado, pois esta estrofe ridiculariza a busca parnasiana pela perfeição métrica.

Remetendo o poema para o momento quando foi escrito, todos os sapos (boi, tanoeiro, pipas e cururu) aparecem enquanto representações alegóricas do campo literário brasileiro. Pensar assim implica ler a alegoria dos sapos como convenção para o leitor. O uso da alegoria no poema ultrapassa o simples emprego de uma figura de linguagem, pois remete aos denominadores daquele sistema: aos próprios literatos e suas obras (BOURDIEU, 1996). Há, dessa forma, a assimilação artística dos sapos para representar criticamente o comportamento dos literatos na disputa por melhores posições no campo.

Assim, a postura de Bandeira corrói o modelo parnasiano por dentro, fazendo emergir de dentro do estilo parnasiano a nova postura estética pela sobreposição do conteúdo à forma. Dessa maneira, podemos dizer que o estilo parnasiano, tributário da arte clássica, trazia em si os germes de sua superação, como bem observado por Mário de Andrade ao se referir a Bilac: seu lirismo é de destruição. O excesso de regras e o culto à forma foram responsáveis por desencadear um movimento de mesma intensidade, mas na direção e sentido opostos. É o que evidencia Mário de Andrade ao 
citar Gorch Fock: "Toda canção de liberdade vem do cárcere" (FOCK apud ANDRADE, 1974, p. 32).

\section{Considerações finais}

O Pré-modernismo configurou-se um período marcado por conflitos no campo artístico e literário brasileiro: de um lado, representantes de uma arte alinhada aos valores clássicos; do outro, representantes de uma crítica global às velhas estruturas mentais, negação do academicismo e ruptura com a cultura oficial, num esforço de penetrar mais fundo a realidade brasileira. Por conta desses conflitos, pode-se identificar uma constante universal: os esforços de Monteiro Lobato, Olavo Bilac, Mário de Andrade e Manuel Bandeira traduzem justamente o movimento constante e processual dos indivíduos em sociedade, na disputa pelo poder para construir sua autoridade e legitimidade.

O conceito de poder deixou de ser amorfo para se transformar numa relação entre duas ou mais pessoas e objetos artísticos; assim, o poder é um atributo destas relações que se mantêm num equilíbrio instável de forças. O poder ocorre no interior do campo/figuração em que "os artistas que fazem arte pura" veem seu poder superior como um sinal de valor humano mais elevado e os artistas que fazem arte anormal, paranóica e mistificada, quando o diferencial de poder é grande e a submissão, inelutável, vivenciam afetivamente sua inferioridade de poder como um sinal de inferioridade humana (ELIAS; SCOTSON, 2000, p. 28). Estigma e marginalização reforçam o tabu imputado a este último grupo, que não dispõe de nenhuma possibilidade de revidar o grupo estabelecido com os mesmo termos depreciativos: "loucos", “extravagantes", "estrelas cadentes" e "frutos de fim de estação, bichados ao nascedoiro".

Os discursos produzidos no contexto do Pré-modernismo refletem justamente esses embates, corroborando para a ascensão dos modernistas no campo literário, ao expor ao ridículo aqueles que se achavam superiores. Com a Semana de Arte Moderna de 1922, os escritores modernistas consolidaram seu poder, ditando a partir de então novos preceitos artísticos. Eles passaram a ser os novos estabelecidos, lutando pela manutenção de sua legitimidade com outros grupos que se propunham a renovação da

\begin{tabular}{|l|l|l|l|l|}
\hline Pensares em Revista & São Gonçalo, RJ & n. 1 & 117-134 & jul.-dez. 2012 \\
\hline
\end{tabular}


literatura brasileira: o grupo encabeçado pelo prestígio intelectual de Graça Aranha; o grupo de escritores católicos do Rio de janeiro, reunidos em torno de Tasso da Silveira (1895-1968), para quem renovar não pressupunha a ruptura brusca com o passado.

\section{Referências bibliográficas:}

ALMEIDA, Dayane Celestino de. Análise semiótica do poema "Os sapos", de Manuel Bandeira. Cadernos de Semiótica Aplicada, v. 5, n. 2, dez. 2007. Disponível em <www.fclar.unesp.br/grupos/casa/artigos/V5n2/CASA2007-v5n2-Art-Almeida.pdf>. Acesso em 07 set. de 2008.

ANDRADE, Mário de. Poesias completas. São Paulo: Martins, 1974.

ATHAYDE, Tristão de. Contribuição à história do modernismo: o pré-modernismo. Vol. I. Rio de Janeiro: José Olympio, 1939.

ATHAYDE, Tristão de. Pressentimentos. Revista Brasileira, Rio de Janeiro, Academia Brasileira de Letras, Ano XII, n. 53, out./nov./dez. 2007, p 55-58. Disponível em $<$ http://www.academia.org.br/abl/media/RB53\%20-

\%20Guardados\%20da\%20Memória.pdf. Acesso em 27 jan. 2009.

BANDEIRA, Manuel. Itinerário de Pasárgada. Rio de Janeiro: Nova Fronteira; Brasília, DF: INL, 1984.

BANDEIRA, Manuel. Poesia completa e prosa. Rio de Janeiro: Nova Aguilar, 1996.

BARBOSA, Alaor. O ficcionista Monteiro Lobato. São Paulo: Brasiliense, 1996.

BILAC, Olavo. Poesias: Panóplias; Via-Láctea; Sarça de fogo; O caçador de esmeraldas; Tarde. Rio de Janeiro: Tecnoprint, 1978.

BOSI, Alfredo. A literatura brasileira: o pré-modernismo. São Paulo: Cultrix, 1969.

BOSI, Alfredo. História concisa da literatura brasileira. São Paulo: Cultrix, 1994.

BOURDIEU, Pierre. As regras da arte. São Paulo: Companhia das Letras, 1996.

BRETON, André. Manifestos do Surrealismo. Lisboa: Moraes Editores, 1985.

CANDIDO, Antonio. Literatura e cultura de 1900 a 1945: panorama para estrangeiros. Literatura e sociedade. São Paulo: Companhia Nacional, 1965.

CARVALHO, José Murilo de. Aspectos históricos do pré-modernismo brasileiro. In: . et alli. Sobre o pré-modernismo. Rio de Janeiro: Fundação Casa de Rui Barbosa, 1988, p. 13-21.

\begin{tabular}{|l|l|l|l|l|}
\hline Pensares em Revista & São Gonçalo, RJ & n. 1 & 117-134 & jul.-dez. 2012 \\
\hline
\end{tabular}


ELIAS, Norbert \& SCOTSON, John L. Os estabelecidos e outsiders: sociologia das relações de poder a partir de uma pequena comunidade. Rio de Janeiro: Jorge Zahar Editor, 2000.

GULLAR, Ferreira. Poesia e realidade contemporânea. Indagações de hoje. Rio de Janeiro: José Olympio, 1989.

HEGEL, Georg W. F. Curso de estética: o belo na arte. São Paulo: Martins Fontes, 1996.

HELENA, Lúcia. Movimentos de vanguarda europeia. São Paulo: Scipione, 1993.

LAFETÁ, João Luiz. 1930: a crítica e o modernismo. São Paulo: Duas Cidades, 1974.

LEITE, Sylvia Helena Telarolli de Almeida. O pré-modernismo em São Paulo. Revista de Letras, São Paulo, UNESP, v. 35, 1995.

LOBATO, Monteiro. Paranóia ou mistificação: a propósito da Exposição Malfatti. Idéias de Jeca Tatu. São Paulo: Brasiliense, 1964.

PASSIANI, Enio. Na trilha do Jeca: Monteiro Lobato e a formação do campo literário no Brasil. Bauru, SP: EDUSC, 2003.

SODRÉ, Nelson Werneck. História da literatura brasileira: seus fundamentos econômicos. Rio de Janeiro: Bertrand Brasil, 1995.

Artigo recebido em: 30 de julho de 2012

Artigo aprovado em: 25 de setembro de 2012.

\section{Sobre o autor:}

Doutorando do Programa de Pós-graduação em Letras da Universidade Federal Fluminense. Possui Licenciatura em Pedagogia (2000) pela Universidade Estadual de Feira de Santana, Licenciatura em História pela Universidade Estadual de Feira de Santana (2004) e de Licenciatura em Letras (Português-Francês) pela Universidade Estadual de Feira de Santana (2009). Especialista em Planejamento e Prática do Ensino pela União Intermunicipal de Cursos Superiores da Bahia (2000) e em Língua Portuguesa pela Universidade Estadual de Feira de Santana (2002). Mestre em Ciências Sociais pela Universidade Federal da Bahia (2006). Atualmente é professor do Colégio Estadual Luís Eduardo Magalhães, da Escola Municipal Dr. Edivaldo Machado Boaventura e da Faculdade Anísio Teixeira.

\begin{tabular}{|l|l|l|l|l|}
\hline Pensares em Revista & São Gonçalo, RJ & n. 1 & 117-134 & jul.-dez. 2012 \\
\hline
\end{tabular}

